\title{
Review \\ JAK2 Variant Signaling: Genetic, Hematologic and Immune Implication in Chronic Myeloproliferative Neoplasms
}

\author{
Dania G. Torres ${ }^{1}\left(\mathbb{D}\right.$, Jhemerson Paes ${ }^{1}\left(\mathbb{D}\right.$, Allyson G. da Costa ${ }^{1,2}$, Adriana Malheiro ${ }^{1,2}$, George V. Silva ${ }^{1,3,4}$, \\ Lucivana P. de Souza Mourão ${ }^{1, * \mathbb{D}}$ and Andréa M. Tarragô ${ }^{1,5, * \mathbb{C}}$ \\ 1 Programa de Pós-Graduação em Ciências Aplicadas à Hematologia, Universidade do Estado do \\ Amazonas (UEA), Manaus 69850-000, AM, Brazil; dgutorr@gmail.com (D.G.T.); \\ jhemersonpaes@gmail.com (J.P.); allyson.gui.costa@gmail.com (A.G.d.C.); \\ malheiroadriana@yahoo.com (A.M.); georgevillarouco@hotmail.com (G.V.S.) \\ 2 Programa de Pós-Graduação em Imunologia Básica e Aplicada, Universidade Federal do Amazonas (UFAM), \\ Manaus 69067-005, AM, Brazil \\ 3 Fundação Oswaldo Cruz-Instituto Leônidas e Maria Deane (Fiocruz), Manaus 69027-070, AM, Brazil \\ 4 Fundação Centro de Controle de Oncologia do Amazonas (FCECON), Manaus 69040-010, AM, Brazil \\ 5 Fundação Hospitalar de Hematologia e Hemoterapia do Amazonas (FHEMOAM), \\ Manaus 69050-001, AM, Brazil \\ * Correspondence: lpsouza@uea.edu.br (L.P.d.S.M.); andrea_s_monteiro@hotmail.com (A.M.T.)
}

\section{check for}

updates

Citation: Torres, D.G.; Paes, J.; da

Costa, A.G.; Malheiro, A.; Silva, G.V.; Mourão, L.P.d.S.; Tarragô, A.M. JAK2 Variant Signaling: Genetic, Hematologic and Immune Implication in Chronic

Myeloproliferative Neoplasms.

Biomolecules 2022, 12, 291.

https://doi.org/10.3390/

biom12020291

Academic Editor: Daniela Grimm

Received: 29 December 2021

Accepted: 5 February 2022

Published: 11 February 2022

Publisher's Note: MDPI stays neutral with regard to jurisdictional claims in published maps and institutional affiliations.

Copyright: (c) 2022 by the authors. Licensee MDPI, Basel, Switzerland. This article is an open access article distributed under the terms and conditions of the Creative Commons Attribution (CC BY) license (https:// creativecommons.org/licenses/by/ $4.0 /)$.

\begin{abstract}
The JAK2V617F variant constitutes a genetic alteration of higher frequency in BCR/ABL1 negative chronic myeloproliferative neoplasms, which is caused by a substitution of a $\mathrm{G}>\mathrm{T}$ at position 1849 and results in the substitution of valine with phenylalanine at codon 617 of the polypeptide chain. Clinical, morphological and molecular genetic features define the diagnosis criteria of polycythemia vera, essential thrombocythemia and primary myelofibrosis. Currently, JAK2V617F is associated with clonal hematopoiesis, genomic instability, dysregulations in hemostasis and immune response. JAK2V617F clones induce an inflammatory immune response and lead to a process of immunothrombosis. Recent research has shown great interest in trying to understand the mechanisms associated with JAK2V617F signaling and activation of cellular and molecular responses that progressively contribute to the development of inflammatory and vascular conditions in association with chronic myeloproliferative neoplasms. Thus, the aim of this review is to describe the main genetic, hematological and immunological findings that are linked to JAK2 variant signaling in chronic myeloproliferative neoplasms.
\end{abstract}

Keywords: JAK2V617F signaling; myeloproliferative neoplasms; clonal hematopoiesis; hemostasis; immunothrombosis; immune response

\section{Introduction}

Chronic myeloproliferative neoplasms (MPNs) are clonal pathologies of hematopoietic stem cells [1], which are characterized by medullar hyperplasia and an accumulation of elements of the myeloid series, and present progressive and effective maturation [2], though without affecting the maturation and differentiation process of the erythroid, granulocytic and megakaryocytic lineage [3]. These changes lead to peripheral blood leukocytosis, increased erythrocyte mass, thrombocytosis and, in more severe cases, medullary fibrosis or leukemic transformation [2].

The first studies on MPNs date from 1845, starting with the description of the first case of chronic myeloid leukemia [4]. Since then, several scholars have engaged in the analysis of the molecular mechanism of chronic myeloproliferative neoplasms, and have determined the semiological aspects of these hematological diseases by observing the signs, symptoms and clinical findings of the investigated patients [5-7].

This clinical view gained a new ally in 1960 with the discovery of the Philadelphia chromosome, which was the first association between a chromosomal abnormality and 
an oncological disease to be described in the history of medicine $[3,4,8,9]$. Since this discovery, the history of MPNs shows them to enter the era of genetics, during which more studies began to be developed and genetic research gained further space in the diagnosis of MPNs (Figure 1).

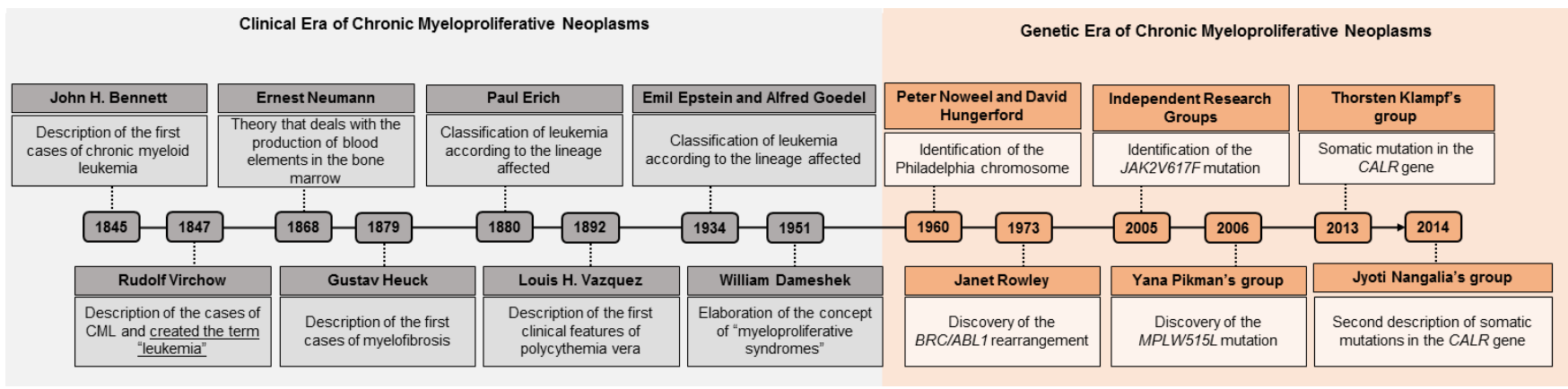

Figure 1. Timeline of myeloproliferative neoplasms. In gray, the clinical era of the MPNs can be seen, which is based on semiological aspects. In orange, the genetic era of MPNs is highlighted, since associated genetic research made it possible to identify genetic alterations that are markers of some MPNs, an important factor that supports diagnosis. CML: chronic myeloid leukemia; BCR/ABL: $\mathrm{BCR} / \mathrm{ABL}$ genetic rearrangement.

Thus, with the discoveries of molecular mechanisms involved in MPNs, the World Health Organization (WHO) determined clinical and laboratory parameters for establishing the diagnosis of these diseases and the WHO, according to its last review in 2016, classifies chronic myeloid neoplasms according to the presence or absence of the Philadelphia chromosome (BCR/ABL1 fusion gene) $[10,11]$. In the BCR/ABL1 positive MPN classification, chronic myeloid leukemia (CML) is responsible for $15-20 \%$ of leukemias worldwide, with an incidence of $1-2 / 100,000$. CML is characterized by the presence of a left shift in granulocytes that results in the identification of less than $20 \%$ of the blasts in peripheral blood $[4,10]$.

Unlike CML (single BCR/ABL1 positive entity, according to the WHO), diseases belonging to the group of BCR/ABL1 negative MPNs have been described, including polycythemia vera (PV), essential thrombocythemia (ET), primary myelofibrosis (PMF), chronic neutrophilic leukemia (CNL), chronic eosinophilic leukemia (CEL) and unclassifiable myeloproliferative neoplasms $[10,11]$. However, polycythemia vera, essential thrombocythemia and primary myelofibrosis are the most frequent diseases in this group $[10,12,13]$, with PMF having the worst prognosis of the three myeloproliferative disorders [12,14]. Similar to CML, in the BCR/ABL1 negative MPNs, criteria are established based on genetic, hematologic and clinical findings, which are organized in the form of major and minor criteria for the diagnosis of PV, ET and PMF, as shown in Table 1.

Among the major criteria of BCR/ABL1 negative MPN, the presence of variants in driver genes stands out, as well as the Janus kinase 2 gene (JAK2-HGNC: 6192), the thrombopoietin receptor gene (MPL-HGNC: 7217) and the calreticulin gene (CALR -HGNC: 1455). Variations in these genes, classified as driver mutations, are determinant in the clinical phenotype observed in MPNs and result in constitutive activation of intracellular signaling pathways [12,19] (Figure 2). Generally, these genomic variations are considered mutually exclusive between BCR/ABL1 negative entities, and their absence does not exclude their diagnosis [10]. However, two variants can be found in the same individual, probably from different neoplastic subclones and those that are often associated with disease progression $[19,21]$.

These driver mutations usually arise again; however, $7 \%$ of cases involve familial aggregation, with autosomal dominant inheritance and incomplete penetrance, and a 5 to 7-fold increased risk for first-degree relatives of the patient with the disease, a risk that may involve the same or different myeloproliferative neoplasms [22-24]. Although JAK2V617F 
is linked to autosomal dominant inheritance, most cases of familial inheritance are not associated with JAK2 gene variants [25]. Nonetheless, mutations in the EPOR, VHL, EPAS1, $H I F$ and EGLN gene have been found in cases of congenital familial polycythemia [26].

Table 1. Diagnosis criteria for classic BCR/ABL1 negative chronic myeloproliferative neoplasms.

\begin{tabular}{|c|c|c|c|}
\hline Neoplasm & Clinical Description & Major Diagnostic Criteria & Minor Diagnostic Criteria \\
\hline PV & $\begin{array}{l}\text { Exacerbated increase in } \\
\text { erythrocyte mass (total red blood } \\
\text { cell count). Generally, both } \\
\text { genders are diagnosed in the } 6 \text { th } \\
\text { or } 7 \text { th decade of life [11]. Annual } \\
\text { global incidence is } \\
0.3-1.5 / 100,000 \text { and survival rate } \\
\text { is } 15 \text { years [2]. }\end{array}$ & $\begin{array}{l}\text { - } \mathrm{Hb}:>16.5 \mathrm{~g} / \mathrm{dL} \text { for men (or Hct: } \\
>49 \%),>16.0 \mathrm{~g} / \mathrm{dL} \text { for women (or } \\
\text { Hct: }>48 \% \text { women), or }>25 \% \\
\text { increase in red cell mass [2]; } \\
\text { Bone marrow biopsy demonstrates } \\
\text { panmyelosis with pleomorphic } \\
\text { mature megakaryocytes; } \\
\text { Presence of the JAK2V617F } \\
\text { mutation or mutations in exon } 12 \text { of } \\
\text { the } J A K 2 \text { gene. }\end{array}$ & 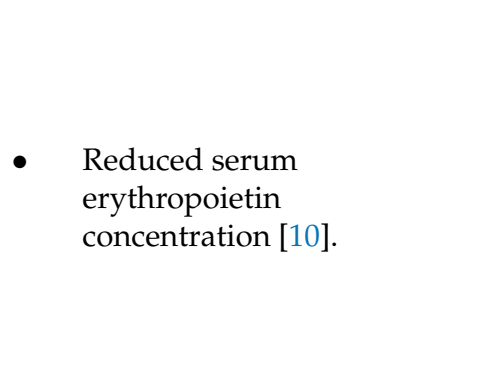 \\
\hline ET & $\begin{array}{l}\text { Increased platelet count with } \\
\text { megakaryocytic hyperplasia. } \\
\text { Annual global incidence is } \\
1.03-2.5 / 100,000 \text { and diagnosis } \\
\text { usually occurs in the } 6 \text { th decade } \\
\text { of life }[15,16] \text {. } \\
\text { Together with PV, it presents high } \\
\text { risks of hemorrhagic and } \\
\text { thrombotic episodes }[3,12,17,18] .\end{array}$ & $\begin{array}{l}\text { Platelet count } \geq 450 \times 10^{3} / \mathrm{mm}^{3} ; \\
\text { Hyperproliferation of } \\
\text { megakaryocytes (some of them } \\
\text { hyperlobulated, and observed in } \\
\text { bone marrow biopsy); } \\
\text { Mild increase in granulopoiesis and } \\
\text { erythropoiesis; } \\
\text { Absence of criteria for PV, CML } \\
\text { and PMF; } \\
\text { Presence of mutations in the JAK2 } \\
\text { gene (JAK2V617F), CARL, MPL. }\end{array}$ & $\begin{array}{l}\text { - Presence of clonal marker or } \\
\text { absence of evidence of } \\
\text { reactive thrombocytosis [10]. }\end{array}$ \\
\hline
\end{tabular}

Pre-fibrotic phase:

- Exacerbated proliferation of the megakaryocytic and granulocytic lineage, absence of reticulin fibrosis $>1$, decreased erythropoiesis and medullary hypercellularity for the patient's age;

Indolent clinical course and has worse prognosis. Patients show increased megakaryopoiesis and extramedullary hematopoiesis

$$
[2,3,19,20]
$$

PMF It has an annual global incidence of 1.5-2.0/100,000, and generally affects individuals over 60 to 70 years of age.
- $\quad$ Absence of criteria for CML, PV and ET;

- $\quad$ Presence of mutations in the CALR gene, JAK2 (JAK2V617F) or MPL or other clonal marker.

Fibrotic phase:

- Megakaryocytic proliferation and atypia, accompanied by grade 2 or 3 reticulin and/or collagen fibrosis;

- Does not meet the criteria for PV, ET, CML, MDS or other myeloid neoplasms;

- Presence of mutations in the CALR, $J A K 2$ (JAK2V617F) or MPL gene or absence of reactive fibrosis.
Pre-fibrotic phase:

- Anemia with no known cause;

- Leukocytosis $11 \times 10^{3} / \mathrm{mm}^{3}$

- Palpable splenomegaly;

- Increased lactic dehydrogenase.

\section{Fibrotic phase:}

- Anemia with no known cause;

- Leukocytosis $11 \times 10^{3} / \mathrm{mm}^{3}$;

- $\quad$ Palpable splenomegaly;

- Increased lactic dehydrogenase

- Leukoerythroblastosis. 


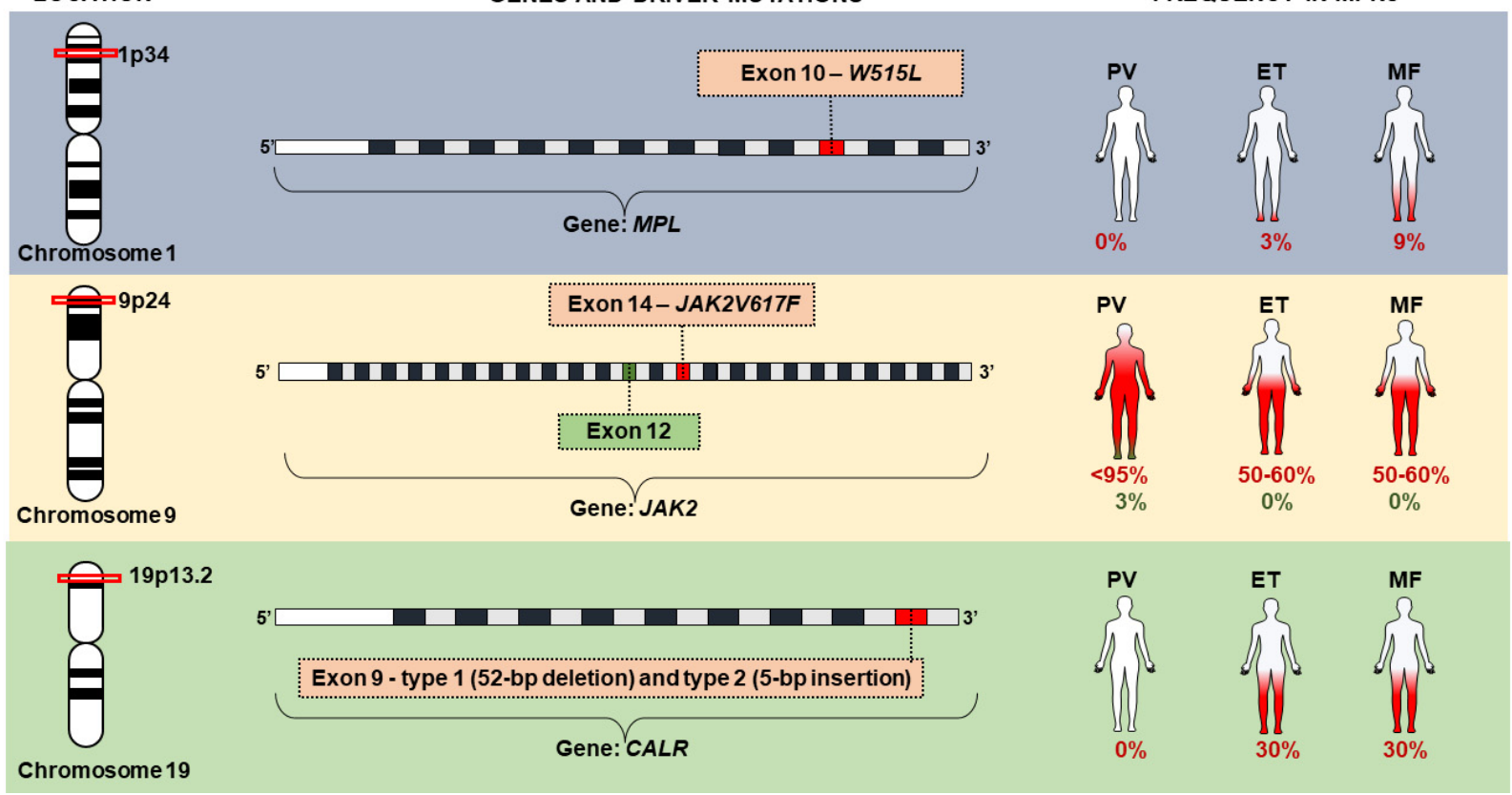

Figure 2. Driver mutations in $J A K 2, M P L$ and $C A L R$ genes associated with chronic myeloproliferative neoplasms (MPNs).

Thus, some determining factors associated with driver mutations should be considered, such as mutations (somatic or germline) that are less specific for MPNs, gender, frequency of the allelic variant and order of acquisition of mutations [27]. In ET and PMF, $12 \%$ of patients do not have any of the driver mutations and are called triple-negative. However, whole-exome sequencing analyses have identified mutations in the JAK2 and MPL genes that have a high rate of leukemic transformation in these patients [28].

Among the driver mutations, the JAK2 $\mathrm{V} 617 \mathrm{~F}$ variant is the most frequent in triggering PV, ET and PMF [10], which are considered to be a major criterion in polycythemia vera, essential thrombocythemia and primary myelofibrosis [5,29-31]. The JAK2V617F variant presents a frequency that is greater than $95 \%$ in individuals with $\mathrm{PV}$, and frequency is from $55 \%$ to $65 \%$ in individuals with ET and PMF, respectively [32] The presence of JAK2V617F causes aberrant signaling of the JAK/STAT pathway, which is an intracellular pathway that is involved in several biological processes, such as hematopoiesis, immune response and activation of other intracellular signaling pathways. Thus, the understanding of JAK2V617F signaling mechanisms and the main cells involved in immunothrombosis may provide a basis for the development of immunotherapeutic strategies in myeloproliferative disorders.

The constitutive signaling of JAK2V617F is linked to high expression of molecules that are related to the inflammatory response, immune dysregulation and manifestation of inflammatory states [33-35], which is a finding that currently constitutes research targets. Cytokines related to natural immunity are the most expressed in chronic myeloproliferative neoplasms, and are detected even in the medullary stroma [34]. This suggests that inflammation is related to bone marrow stromal initiation, which promotes medullary fibrosis and clonal expansion [35]. In peripheral blood, the interaction between JAK2V617F positive hematopoietic cells, endothelium and immunological molecules enhances the immunothrombosis mechanism, thus constituting an independent and unfavorable prognostic factor in the survival of patients with MPNs [36].

As such, the understanding of the JAK2V617F signaling mechanisms and the main cells involved in immunothrombosis may provide a basis for the development of immunotherapeutic strategies in myeloproliferative disorders. Therefore, in this review, we describe the $J A K 2 \mathrm{~V} 617 \mathrm{~F}$ variant and its implications for genomic instability and immune dysregulation, as well as its relationship to the onset of chronic inflammation through cellular mechanisms. 


\section{JAK2V617F: Genetic Implication in Signaling Pathways}

In 2005, the molecular basis of chronic myeloproliferative diseases was described, with the JAK2V617F variant (dbSNP ID: rs77375493) characterized by a transversion-type base substitution at nucleotide $1849(1849 \mathrm{G}>\mathrm{T})$ of exon 14 of the JAK2 gene encoding a valine through a phenylalanine at position 617 (V617F) [37-39]. Metabolically, this genetic alteration leads to a gain-of-function mutation in JAK2, a cytoplasmic tyrosine kinase with a central role in the signal transduction of hematopoietic growth factor receptors [40,41]. This change occurs in the pseudokinase domain of JAK2, interrupting the auto-inhibitory effect, and resulting in constitutive phosphorylation, which generates hyper phosphorylation, deregulates cellular signals downstream of the JAK2/STAT5 signaling pathway (Figure 3), interferes with the correct signaling of erythropoietin (EPO) receptors, granulocyte colony stimulating factor (G-CSF), granulocyte-monocyte colony stimulating factor (GM-CSF) and thrombopoietin (TPO), and also increases cell proliferation and resistance to apoptosis [ClinVar ID: NM_004972.3 (JAK2): c.1849G > T (p. V617F))] [3,41,42].

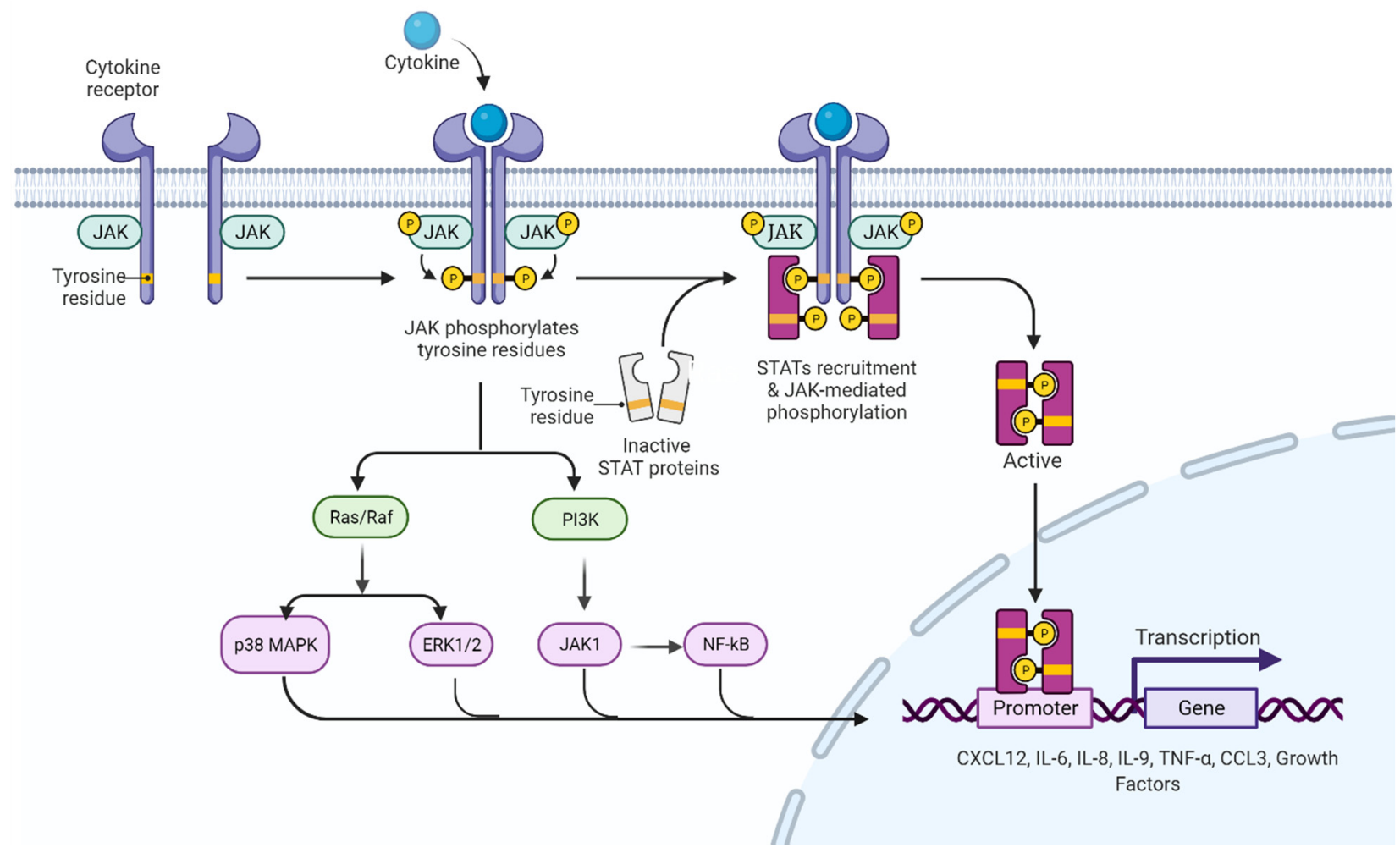

Figure 3. JAK/STAT signaling pathway. In the absence of cytokines, the JAK protein remains inactive in regions close to the intracellular domains of the receptor. When a cytokine binds to a receptor, $J A K$ proteins and intracellular domains of the receptor are phosphorylated, activating and recruiting STAT proteins, which dimerize and translocate to the nucleus to initiate the transcription process of genes involved in cell proliferation. In addition to the activation of the JAK/STAT pathway, there is an interconnection with other intracellular signaling pathways, among the most prominent are the Ras/Raf/MAPK pathway and the PI3K pathway; the latter manifesting interconnection with JAK1 proteins, which indirectly activate the NFkB pathway, the transcriptional factors that activate the production of cytokines (among them CXCL12, IL-6, IL-8, IL-9, TNF- $\alpha$ and CCL3) and the growth factors identified in the inflammatory profile of individuals with chronic myeloproliferative neoplasms. JAK: Janus kinase protein; STAT: signal transducers and activators of transcription; MAPK: mitogen-activated protein kinase; PI3K: phosphoinositol kinase 3; JAK1: Janus kinase class 1 protein; NFkB: light chain nuclear factor B-cell kappa; CXCL12: chemokine 12 with CXC motif; IL-6: interleukin 6; IL-8: interleukin 8; IL-9: interleukin 9; TNF- $\alpha$ : tumor necrosis factor alpha; CCL3: chemokine ligand 3. 
Analysis of germline cells, such as buccal cells, $\mathrm{T}$ cells or both, in cases of familial clustering of myeloproliferative disorders, show absence of the variant allele. In this scenario, the JAK2V617F variant is not the first event that leads to disease $[22,40,43]$. The $46 / 1$ haplotype is a $280 \mathrm{~Kb}$ long region of chromosome $9 \mathrm{p}$ that includes three genes, including JAK2. The part called "GGCC" corresponds to the four main polymorphisms of this haplotype (rs3780367, rs10974944, rs12343867 and rs1159782) that start in intron 10 and end in intron 15 of the $J A K 2$ gene [44,45] (Figure 4). These four variants are in complete linkage disequilibrium, and are inherited together [44,46]. This haplotype is described as one of those responsible for the processes that precede the acquisition of JAK2V617F, increasing the mutation rate of the $J A K 2$ locus and the probability of acquiring mutations with selective advantage, which is the case of $J A K 2 \mathrm{~V} 617 \mathrm{~F}$ and which, in turn, causes clonal myeloproliferative disorders [31,45-48].

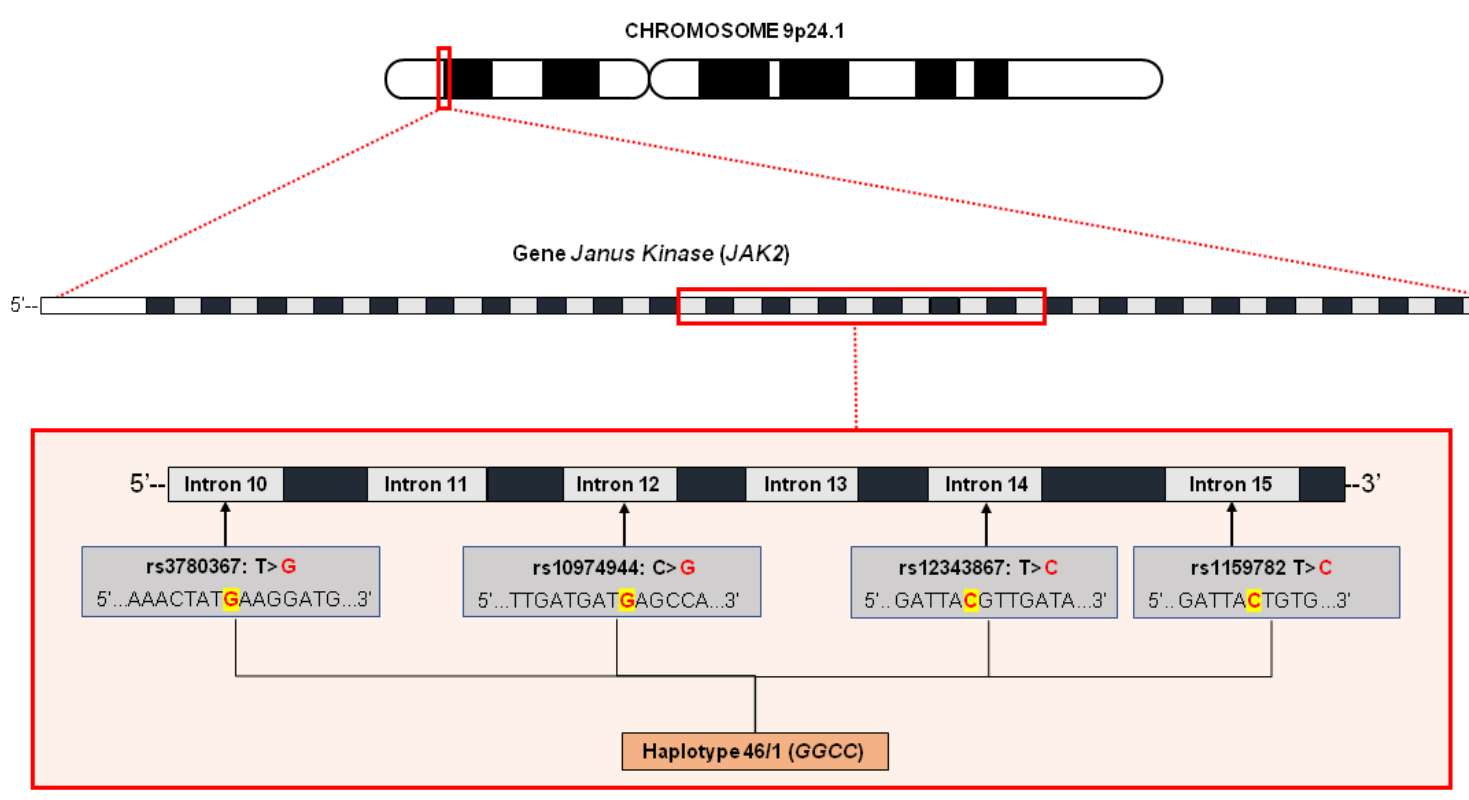

Figure 4. Characterization of the 46/1 haplotype without JAK2 gene. The haplotype, also called GGCC, is altered by four variants located in intron 10 (rs3780367: T > G), intron 12 (rs10974944: C > G), intron 14 (rs12343867: T > C) and intron 15 (rs1159782: T > C). It is believed that the presence of this haplotype conditions an increase in the mutation rate of the gene locus in question, thus resulting in the emergence of mutations with a selective advantage, as in the case of JAK2V617F.

It is still unclear how the same mutation is associated with three different disease phenotypes. Possible explanations include inter-individual differences in genetic background, acquisition of additional genetic alterations or in the target cell for transformation [43]. Thus, JAK2V617F may even compromise the functionality of cell lines that integrate the hematopoietic and inflammatory processes.

\section{Implications of the JAK2V617F Variant in Positive Cells and Immunothrombosis}

Recent studies have described the relationship between the mechanisms and immune responses expressed by cells involved in the innate and adaptive immune system (neutrophils, monocytes, macrophages, lymphocytes, endothelial cells and platelets) with important molecules of hemostasis, which is a phenomenon currently called immunothrombosis. The immunothrombosis process is multifactorial, generally mediated by hypercellularity, and causes changes in plasma proteins that are important in the process of hemostasis and activation of endothelial molecules, adhesion product and cell function [49-51]. Hypercellularity in peripheral blood is a result of the constitutive activation of the JAK2/STAT5 pathway, which increases blood viscosity through cell-cell-endothelial interaction, and even forms plasma complexes [49-53]. Thus, the characteristic leukocytosis, erythrocytosis 
and thrombocytosis in patients with MPNs not only reflect quantitative alterations in hematopoiesis, but also qualitative alterations in the immune response and hemostasis, through the expression of molecules that favor the activated prothrombotic phenotype [50]. It has been well described in the literature that vascular complications of arterial or venous type affect up to one third of individuals with MPNs and constitute one of the main causes of mortality in these individuals [51,52,54-56], especially in ET [53].

JAK/STAT pathway activation is involved in the inflammatory response by directly interconnecting with other intracellular signaling pathways involved in cytokine production. Di Rosa et al. [57] demonstrated that CD34+ cells from individuals with PMF showed dysregulated activation of the JAK2/STAT1 pathway and significant activation of genes involved in the IFN- $\gamma$ pathway (IFN- $\gamma$, IRF1 and IFNGR2) compared to healthy individuals, and noted that IFN I and II have been described as mediators of antitumor immunity through activation of the PI3K/AKT/mTOR pathway, which, in turn, activates the NFkB pathway and promotes antigen presentation and cytokine secretion [56].

On the other hand, the action of programmed death protein (PD-1), mediated by IFN- $\gamma$ expression, which is vital in the tumor recognition process, is dysregulated in patients with MPNs, indicating that JAK2V617F positive hematopoietic cells from individuals with MPNs express the PD-L1 ligand, which is a mechanism that blocks the action of Th lymphocytes and contributes to the immune escape of neoplastic cells [58,59]. At the same time, this results in JAK2/STAT3 signaling up to three times greater than normal, which is a fact that is linked to tumor progression associated with inflammation [55]. The experimental murine assay carried out by Prestipino et al. [60] demonstrated oncogenic activity of JAK2 with consequent phosphorylation of STAT3 and STAT5 that facilitates the promotion of PD-L1 activity in JAK2V617F positive cells and affects the cell progression cycle of $\mathrm{T}$ cells, which is a finding associated with more advanced states of MPNs.

In PMF, there is an altered regulation of T cells, which is determined by the significant activation of CD8+ T lymphocytes, and this finding is linked to the activation of HLA class I molecules, chronic inflammation and immune dysregulation, thus favoring the activation of fibroblasts and contributing to the progression of medullary fibrosis and cytopenias [54]. Interestingly, the constitutive activation of JAK2V617F not only produces alterations in the cellular immune response through classical pathways, it also favors the indirect activation of hypoxia inducible factors (HIF) and erythropoietin (EPO) secretion through the NFkB pathway, generating an hypoxic state of variable severity that favors tissue atrophy and production of erythroid progenitors, an event that contributes to the production of pro-inflammatory cytokines in peripheral blood [58].

Therefore, JAK2V617F complexly deregulates intercellular signaling through activation of cytokine production and interruption of homeostasis and cytotoxicity of immune cells [48]. Immune dysregulation in individuals with MPNs is confirmed by high concentrations of IL-6, IL-8, GM-CSF, HGF, VEGF, b-FGF and TGF- $\beta$ in medullary stromal cells and increased production of IL-6, IL-8, IL-9, CCL3, CCL4 and TNF- $\alpha$ in peripheral blood cells [59].

The inflammatory picture is related to the excess of cytokines (generally type I IFN and belonging to the IL-6 family), a product of the constitutive signaling of the JAK2/STAT5/STAT3 pathway, which directly activates other intracellular signaling pathways committed to the production of pro-inflammatory cytokines [28]. PI3K, MAPK, NFkB and HIF1- $\alpha$ pathways induce tumorigenesis [31] and expression of mediator mechanisms of inflammation in neutrophils, monocytes, macrophages, lymphocytes and platelets [60] (Figure 5).

\subsection{Neutrophils}

Neutrophils constitute a large percentage of leukocytes in peripheral blood and are involved in immune response processes against antigens. Neutrophils from individuals with MPNs have abundant basal amounts of reactive oxygen species (ROS), especially in patients with PMF, which are induced by JAK2-dependent ERK signaling and constitutive phos- 
phorylation, producing NADPH oxidase and neutrophil activation by myeloperoxidase expression [61].

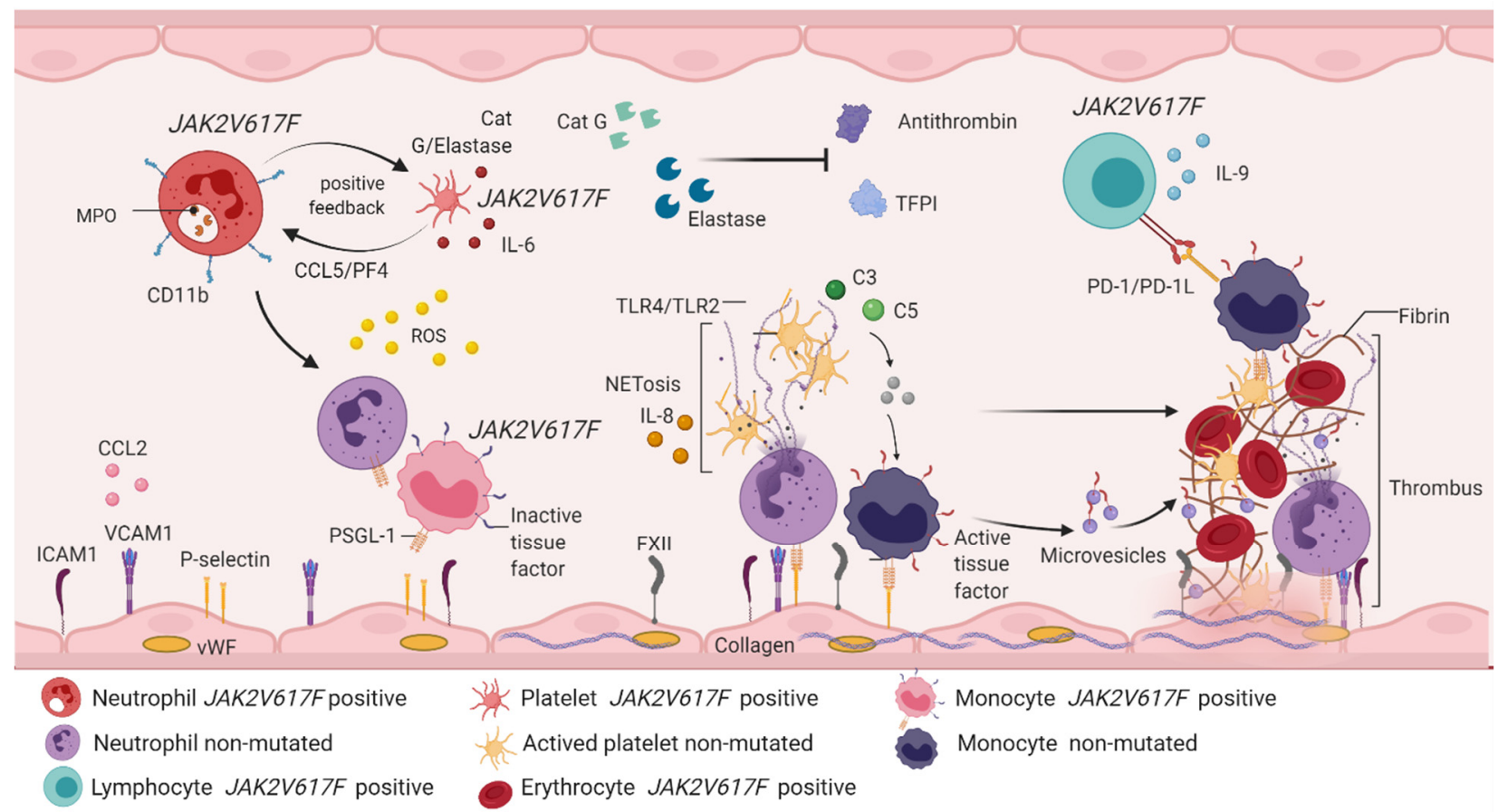

Figure 5. Immunothrombosis involves the participation of hematopoietic cells and immune system cells. JAK2V617F positive neutrophils express CD11b on the cell surface and secrete enzymes such as MPO, cathepsin G and elastase. The release of cathepsin G and elastase activates CCL5/PF4 signaling in $J A K 2 \mathrm{~V} 617 \mathrm{~F}$ positive platelets, which is an interaction that creates positive feedback between platelets and neutrophils, and favors the production of IL-6 and ROS. Free cathepsin and elastase inhibit the function of antithrombin and plasma TFPI, contributing to the thrombotic phenotype. Unmutated neutrophils are activated by the action of ROS, which recruit and activate monocytes with PSGL-1 expression and inactive tissue factor. Both cells manifest rolling and endothelial adhesion by binding adhesion molecules expressed in endothelial cells (ICAM1, VCAM1, P-selectin, CCL2 and FXII). Simultaneously, endothelial cells are activated by the action of ROS, releasing vWF and collagen, thus forming a platelet-monocyte-neutrophil interaction, which favors the discharge of genetic and protein material from the neutrophil, starting with NETosis. This brings with it the expression of IL-8 and activation of TLR4/TLR2 in platelets, a fact that allows the expression of receptor glycoproteins and, therefore, platelet aggregation. In NETosis, erythrocytes are recruited and release hemoglobin and increase ROS production. The complement system is active in response to activation of immune cells, especially through the action of $\mathrm{C} 3$ and $\mathrm{C} 5$, which induces signaling from $J A K 2 \mathrm{~V} 617 \mathrm{~F}$ positive monocytes and non-mutated monocytes. JAK2V617F positive monocytes express PD-1L, which immediately activates PD-1 in JAK2V617F lymphocytes, a mechanism responsible for the evasion of the immune response described in chronic myeloproliferative neoplasms. Recruitment and activation of immune and hematopoietic cells benefits the conversion of fibrinogen into fibrin, giving rise to thrombus formation, the main factor involved in vascular complications described in myeloproliferative neoplasms. MPO: myeloperoxidase; CCL5: chemokine ligand 5; PF4: platelet factor 4; IL-6: interleukin 6; ROS: reactive oxygen species; TFPI: plasma tissue factor inhibitor; PSGL-1: P-selectin ligand 1; ICAM-1: intercellular adhesion molecules 1; VCAM-1: vascular cell adhesion molecule 1; CCL2: chemokine ligand 2; FXII: factor XII; vWF: Von Willebrand factor; IL-8: interleukin 8; TLR2/TLR4: Toll-like receptor 2/4; C3: complement component 3; C5: complement component 5; PD-1: programmed death protein; PD-L1: programmed death protein ligand 1.

The activation and recruitment of leukocytes contributes to the formation of neutrophil extracellular traps (NETs), which are networks made up of genetic material and 
protein derived from neutrophils, and which favor cell activation, production of reactive oxygen species, platelet activation and aggregation and endothelial damage [62]. Activated neutrophils express CD11b on the cell surface and secrete elastase and myeloperoxidase, which favors the chemotaxis of neutrophils, monocytes and macrophages and facilitates endothelial adhesion [63-66]. Simultaneously, the expression of $\beta 1$ and $\beta 2$ integrins in recruited neutrophils is favored, and glycoproteins are expressed by interconnection of the JAK/STAT pathway with Rap1-GT-Pasa, which have affinity for vascular cell adhesion molecules (VCAM-1) and for intercellular adhesion molecules (ICAM-1) expressed by endothelial cells [67-70], thus enhancing endothelial adhesion. Likewise, expression of P-selectin ligand 1 (PSGL-1) and cell adhesion molecule type 1 (MAC-1) in neutrophils contributes to the release of cathepsin $\mathrm{G}$ (a neutrophilic degradative enzyme important in the elimination of pathogens and in the degradation of components in inflammatory sites), which, together with elastase, determines a positive feedback through the expression of CCL5 and platelet factor 4 (PF4) in platelets, stimulating the expression of P-selectin and GPIba in platelets and favoring the thrombogenesis process [52].

An interesting finding is that both elastase and cathepsin G block the tissue factor pathway inhibitor (TFPI) and antithrombin (AT), which are two potent natural anticoagulants, and this contributes to the activation of the proteinase 4 receptor (PAR4) pathway in platelets, Von Willebrand factor exposure and initiation of the coagulation cascade [51,71].

Thus, neutrophil activation allows the release of DNA-histone complexes (especially $\mathrm{H} 3$ and $\mathrm{H} 4$ ) that induce the production of NETs and platelet activation via NF-kB and TLR2 and TLR4 function [67], with a consequent expression of GPaIlb3 contributing to platelet aggregation and formation of thrombin in the extrinsic pathway [68]. HistoneMPO complexes have also been found in the plasma of individuals with MPNs and to be associated with high levels of LDH [61]. As such, NETosis plays a crucial role in tumor expansion in MPNs by enhancing immunothrombosis and activating hemostasis, thus forming a repetitive cycle [66].

Since we now know about the active participation of neutrophils in the process of immunothrombosis in MPNs, there has been great interest in identifying neutrophil subtypes involved in this mechanism. Tumor-associated neutrophils (TANs), also classified as PMN-MDSCs, can be subdivided into N1 (neutrophils with anti-tumor action) and N2 (neutrophils with pro-tumor action) [68,72,73], both in human and murine models, and are found in circulation and in the microenvironment of patients with tumorigenic and inflammatory conditions [70]. TANs directly contribute to the angiogenesis process through significant release of ROS and consequent formation of NETs through expression of CD11b and elastase [71].

The presence of TANs is also documented in processes of infiltration, invasion and metastasis of solid tumors, such as melanoma, advanced gastric carcinoma, infantile brain tumor [72] and even in cases of acute pancreatitis [74-77]. In these types of tumors, TANs are sensitive to microenvironmental signals caused by the secretion of CXCL1, CXCL2, TNF- $\alpha$, IFN- $\gamma$ and IL-8 [70], which favors local invasion, functional overexpression of neutrophils and functional suppression of T lymphocytes. However, the role of TANs in hematologic malignancies has been sparsely described. In 2019, the study by Podaza and Risnik [78] aimed to detect TANs in individuals with chronic lymphocytic leukemia (CLL) and found that the proportion of TANs in patients with CLL was greater, with high concentrations of IL-8, an important molecule in the induction of NETs. Unfortunately, due to the scarce description of surface markers in this classification of neutrophils, the research does not discriminate the TAN (N1/N2) phenotypes found, which are defined by the production capacity of ROS and NETs. Nonetheless, some recent studies have aimed to describe the phenotyping of these neutrophil subpopulations to better characterize them, especially their role in hematological diseases. 


\subsection{Platelets}

Platelet activation and dysfunctionality is a well-described phenomenon in thrombotic and hemorrhagic processes in patients with MPNs, and it is worth mentioning that some platelet markers, such as P-selectin, CD41L, $\beta$-thromboglobulin, PF4 and platelet-derived growth factor (PDFG), have been detected in high concentrations in the plasma of individuals with ET and PV [52,54], which are biomarkers associated with thrombotic complications. The expression of these markers induces a hemostatic response through exposure and activation of tissue factor (a product of endothelial damage), directly activating the extrinsic pathway of the coagulation cascade and consequent fibrin production. In this process, activated platelets expose negatively charged phospholipids that confer proteolytic reaction of coagulation factors, acting as mediators between coagulation and inflammation through activation of the complement cascade, especially of C3 and C5 molecules [66].

Interestingly, patients with MPNs can also manifest high basal levels of phosphatidylserine in the platelet membrane, which in turn develops a pro-coagulant function, and which is a finding that demonstrates that platelets are the central target in the development of vascular and inflammatory complications in MPNs [75]. Thus, the presence of the JAK2V617F mutation could potentiate platelet activation and contribute to persistent thrombosis in these patients.

On the other hand, the constant circulation of complexes and activation of platelet proteins can expose molecules derived from endothelial cells, favoring endothelial activation and damage through TLR-4 signaling in platelets [76]. As such, endothelial activation is promoted by high levels of reactive oxygen species, which are released by neoplastic platelet-neutrophil complexes that lead to exposure of Von Willebrand factor, collagen, platelet-endothelial cell adhesion molecules (PECAM), E-selectins and thrombomodulin, as well as CD40L (an important tissue factor inducer), which are all molecules that favor endothelial adhesion and are directly involved in the activated thrombotic picture $[75,79]$. In the active process of hemostasis, the expression of some biomarkers, such as thrombin, D-D, FVIII, fibrinogen, CD40L and platelet integrins, is detected; that, together with tissue factor, protein S, protein C, Von Willebrand factor and P-selectins, favors the perpetuation of active hemostasis, cell adhesion and recruitment of leukocytes and erythrocytes [76]. Although platelets form complexes with neutrophils, platelet-monocyte aggregates have also been found, especially in patients with ET [77].

The interaction between platelets and endothelial cells most likely contributes to the production of soluble selectins and the reduction of nitric oxide (a consequence of high levels of reactive oxygen species and MPO), which benefits the laminar vessel reduction and vascular obstruction [51,80]. Poisson et al. [81] provide confirmation of this, in which endothelial cells showed a dysfunction of the nitric oxide pathway, the cause of the accumulation of microvesicles derived from MPO-carrying erythrocytes, which increased endothelial oxidative stress and compromised the vascular response to vasoconstrictors. This implies a possible participation of erythrocytes in this process. Therefore, in hematopoietic cells, oxidative stress and chronic inflammation status is favored by the vicious cycle of biomacromolecule production that contributes to genomic instability, mutation acquisition, tissue damage and acute leukemia transformation [82,83].

On the other hand, hemorrhagic conditions can also be presented in patients with MPNs, and are linked to increased platelet consumption (product of thrombogenesis) due to the absence of a connection with high molecular weight multimers of the Von Willebrand factor and dysfunctionality of platelet-dense granules [84]. However, hemorrhagic complications are more often described in individuals with PMF and PV, compared to those with ET [85]. An important finding about this is that individuals with mutated ASXL1-PMF have a poor prognosis and a high risk of complications in hemostasis [86]. Unfortunately, a relationship between mutations in ASXL1 and the development of bleeding disorders in patients with PMF has not yet been established.

Matsuura et al. [87] observed a significant reduction of platelet-dense granules in $J A K 2 \mathrm{~V} 617 \mathrm{~F}$ positive platelets, suggesting that hyperactivation in JAK2 affects the devel- 
opment of an ensemble of these granules in platelets in the thrombopoiesis process. As a result, the role that JAK2 signaling plays in the control of dense granules in platelets has never been reported.

\subsection{Monocytes}

Monocytes play an important role in the process of immunothrombosis, which is also an independent and unfavorable prognostic factor in the survival of patients with PV and PMF, since they are mediators of inflammation, thrombosis and medullary fibrosis due to the secretion of high concentrations of cytokines and the presentation of an unbalanced response to IL-10. In the bone marrow, the pro-inflammatory cytokine signaling promotes the interaction between malignant clone and stromal cells, which stimulates osteoclastogenesis in the endosteal niche and causes the emergence of fibrocyte clones involved in the induction of medullary fibrosis in PMF [36]. This mechanism is promoted through cell cycle dysregulation in fibroblasts, and accelerates the mal-differentiation process so that it loses the ability to repair hematopoietic tissue (may be a product of the oxidative stress) and contributes to marrow fibrosis [88].

By using single-cell RNA-seq, Leimkuhler et al. [89] demonstrated that transcriptomics of mesenchymal stromal cells of primary myelofibrosis patients show loss of hematopoietic niche support, decreased multipotent progenitor status cell, upregulated JAK/STAT and TGF- $\beta$ signaling and upregulation of extracellular matrix proteins like collagen.

Indirectly, monocyte activation is determined by exposure to pathogen-associated molecular patterns (PAMPs) and damage-associated molecular patterns (DAMPs), thus providing exposure to tissue factor and CD25 and benefiting activation of proteins with procoagulant action and NFkB signaling [90].

On the other hand, monocyte activation may be favored by the expression and binding of PSGL-1 to platelet P-selectin, favoring the expression of inflammatory cytokines [71]. Therefore, platelet-monocyte interaction induces a pro-inflammatory phenotype through the expression of CD147, PSGL-1, EP1/EP2 and COX-2 as well as the activation of integrins that contribute to endothelial adhesion and monocyte recruitment [91]. Confirmation of this is found in the study by Wei Wang et al. [52], in which JAK2V617F positive macrophages manifested a high expression of inflammatory cytokines (IL-1 $\beta$, IL-6 and TNF- $\alpha$ ), nitric oxide synthase (iNOS), ligand-2 chemokine (CCL2) and activation of the MAPK pathway, and they noted that monocytes showed remarkably distinct rolling and cell adhesion when compared to wild-type cells.

It is important to mention that macrophages are subdivided into type M1 and type M2, that both cell subtypes are activated by the NFkB signaling pathway, and that they have cellular functions similar to N1 and N2, respectively [92]. M2 is the largest component in neoplastic tissues, and directly contributes to the tumor environment, proliferation, angiogenesis and release of cytokines that lead to neoplastic expansion [93]. However, M2 has been sub-classified into M2a, M2b and M2c; though it is worth noting that monocyte/macrophage accumulation of $\mathrm{M} 2 \mathrm{~b}$ can promote growth, invasion and recurrence of cancers in vitro and in vivo [93].

In the study by Molitor et al. [94], it was observed that JAK2V617F positive M2 in patients with PMF showed greater capacity for colony formation through the secretion of pro-fibrotic molecules, such as CCL2, IL-8, matrix metalloproteinase-9 (MMP9), galectin 3 (LGALS3) and osteopontin (SPP1), which drive the proliferation and production of collagen. Nonetheless, further research is needed regarding the role of macrophage subclasses in different MPN phenotypes.

\subsection{T Helper and Natural Killer Lymphocytes}

Although lymphocytes are not well described in MPNs, these cells may also be involved in immune dysregulation. T lymphocytes have a long lifespan and this possibly contributes to greater signaling of disruptive effects in the immune system [95]. In some PMF cases, T lymphocytes carry 3-83\% of variant allele frequency of $J A K 2 \mathrm{~V} 617 \mathrm{~F}$, accom- 
panied by abnormalities in the karyotype, such as 13q-, 20q-, monosomy 7 and inv(3). It is noted that these last two chromosomal alterations confer an unfavorable prognosis [95-98]. Just as in lymphocytes, the role of natural killer (NK) cells in MPNs has not been widely described.

NK cells are associated with the control of tumor growth and metastasis, which indicates that NK cell deficiency is very rare and is generally linked to lymphoproliferative disorders [98]. However, the study by Arantes [99] demonstrated that NK cell JAK2V617Fpositive patients had lower NKCD16 + CD56 dim counts compared to NK cell JAK2V617Fnegative patients, especially those with PV and PMF, which is a finding that suggests that NK cells may be defective in MPNs. Although there have been some investigations into the role of lymphocytes and NK cells in these hematological diseases, further research is needed in order to elucidate their role in the evolution of these diseases and in the development of immunothrombosis in MPNs.

\section{Summary and Perspectives}

The clinical approach to patients with myeloproliferative neoplasms is based on the control of vascular complications, both arterial and venous, since these are events that result in the main cause of morbidity and mortality due to hematological diseases. According to recent investigations, thrombohemorrhagic complications are attributed to the presence and high allelic frequency of $J A K 2 \mathrm{~V} 617 \mathrm{~F}$ [100], suggesting that the presence of the $J A K 2$ $46 / 1$ haplotype has not been related to the production of inflammatory biomarkers that can be expressed in immunothrombosis [101]. Likewise, the link between JAK2V617F and dysregulations in the immune response and hemostasis is well-described and associated with the interconnection of the JAK/STAT pathway with other intracellular signaling pathways, such as PI3K/AKT, Ras/Raf/MAPK and NFkB, in the apoptotic process and in the production of inflammatory molecules [59]. In addition, next-generation sequencing investigations have described other genes involved in these signaling pathways (FLT3, GNAS, KIT, KRAS, NF1, NRAS, PTPN11 and SH2B3), in epigenetic regulator genes (TET2, ASXL1, DNMT3A and $E Z H 2$ ) and negative regulator genes of the JAK2 signaling pathway (SOCS and $C B L$ ), since they showed a strong association with dysregulations in cytokine production and secretion [102,103]. These could be excellent research targets in pathogenic mechanisms of MPN, and be employed as predictors of worse clinical outcome, stratification risk or even as leukemia transformation predictors [104].

The International Working Group-Myeloproliferative Neoplasms Research and Treatment (IWG-MRT) established a prognostic algorithm for thrombotic complications in common with $B C R / A B L 1$ negative chronic myeloproliferative neoplasms, especially in PV and ET, based on the variables of age ( $>60$ years), percentage of homozygosity of JAK2V617F and history of thrombotic events, which are factors that define the categories of low risk, very low risk, intermediate and high risk of thrombotic and vascular complications [5].

Cytoreductive therapy in individuals with PV, ET and PMF is often scrutinized but widely used to alleviate the clinical picture and reduce the risk of these complications. Thus, the drug of choice in individuals with PV and ET is hydroxyurea (HU). Unfortunately, resistance or intolerance to HU have been described in 15-20\% of patients with MPN [105]. This phenomenon is a challenge in the treatment of these patients because it reduces the therapeutic options and increases disease progression or the thrombotic risk [105]. Many investigations regarding this have been carried out and suggest that the existence of other molecular alterations in the kinase domain of JAK2 protein or in non-driver genes could be the reason for the pharmacological refractory [106,107].

Ruxolitinib, a drug approved a few years ago by the FDA, is also considered an excellent pharmacological choice in patients resistant to HU in PV [108]. However, murine models demonstrated that its pharmacological action does not present anti-leukemic activity in vivo in the bone marrow [109], which is a finding that could suggest a possible contribution from other deregulated cellular signaling, and is a target that would also be interesting in the prognosis of these patients. In PMF, the treatment of choice is HU, and 
using ruxolitinib for cases refractory to HU and patients classified as high risk [109]. In young high-risk patients with PMF, allogeneic hematopoietic stem cell transplantation is considered. Nevertheless, the use of cytoreductive drugs for reticular fibrosis or collagen would increase the chances of survival in these individuals; it is worth noting that PMF is the $B C R / A B L 1$ negative chronic myeloproliferative neoplasm with the greatest association with leukemic transformation.

On the other hand, inhibition of platelet function in $B C R / A B L 1$ negative chronic myeloproliferative neoplasms is one of the main functions, since, as previously described, platelets play a central role in the process of immunothrombosis. Thus, the use of antiplatelet agents reduces the rate of occurrence and recurrence of thrombo-hemorrhagic and inflammatory events [80]. Low molecular weight heparin, aspirin and clopidogrel are the main drugs used to control platelet activation. Although they are the most frequently used drugs in these diseases, the use of new drugs that inhibit the expression of platelet receptors, platelet adhesion molecules and cytokines would favor the reduction of thrombus formation and, consequently, the development of immunothrombosis [5]. Likewise, inhibition of the expression of integrins, adhesion molecules and other membrane proteins in neutrophils, monocytes, lymphocytes and endothelial cells constitutes a promising strategy in individuals with $B C R / A B L 1$ negative chronic myeloproliferative neoplasms as treatment targets [66], especially in those with drug resistance and categorized as high risk.

Despite the detection of microvesicles, cellular complexes and other inflammatory markers have been comprehensively discussed in MPN, and detection of mi-RNAs is actually considered a metabolic response marker, before, during and after lymphoma treatment [110]. Moreover, the advance in molecular techniques leads us to the development of noninvasive techniques, such as liquid biopsy, that could be a potential tool, especially in non-solid cancers, for prognosis and monitoring indicators in hematologic malignancies [111]. Currently, analyzing the circulating cell-free (cf)-DNA is proposed as a noninvasive tool for use in the diagnosis and prognosis of hematologic malignancies, which could be employed to differentiate between MPN subtypes, as well as to predict the development of thrombotic complications [111,112].

Author Contributions: Conceptualization: D.G.T., J.P., A.M.T. and L.P.d.S.M.; writing—original draft preparation: D.G.T., J.P., A.M.T. and L.P.d.S.M.; writing-review and editing: A.M.T., L.P.d.S.M., A.G.d.C., G.V.S. and A.M. All authors have read and agreed to the published version of the manuscript.

Funding: This work was funded by Fundação de Amparo à Pesquisa do Estado do Amazonas (FAPEAM) [Pró-Estado Program—\#002/2008, \#007/2018 and \#005/2019; POSGRAD Program \#006/2021, Rede Genômica de Vigilância em Saúde do Estado do Amazonas (REGESAM), Conselho Nacional de Desenvolvimento Científico e Tecnológico (CNPq) and Coordenação de Aperfeiçoamento de Pessoal de Nível Superior (CAPES). The funders had no role in study design, data collection and analysis, decision to publish or preparation of the manuscript.

Institutional Review Board Statement: Not applicable.

Informed Consent Statement: Not applicable.

Data Availability Statement: Not applicable.

Conflicts of Interest: The authors declare no conflict of interest.

\section{References}

1. Tremblay, D.; Yacoub, A.; Hoffman, R. Overview of Myeloproliferative Neoplasms: History, Pathogenesis, Diagnostic Criteria, and Complications. Hematol. Oncol. Clin. N. Am. 2021, 35, 159-176. [CrossRef] [PubMed]

2. Chauffaille, M. Neoplasias mieloproliferativas: Revisão dos critérios diagnósticos e dos aspectos clínicos. Rev. Bras. Hematol. Hemoter. 2010, 32, 308-316. [CrossRef]

3. Nangalia, J.; Green, A.R. Myeloproliferative neoplasms: From origins to outcomes. Hematology 2017, 1, 470-479. [CrossRef] [PubMed]

4. Tefferi, A. The history of myeloproliferative disorders: Before and after Dameshek. Leukemia 2008, 22, 3-13. [CrossRef]

5. Tefferi, A. Myeloproliferative neoplasms: A decade of discoveries and treatment advances. Am. J. Hematol. 2016, 91, 50-58. [CrossRef] 
6. Means, R.T. JAK2 V617F and the evolving paradigm of polycythemia vera. Korean J. Hematol. 2010, 45, 90. [CrossRef]

7. Bortolheiro, T.C.; Chiattone, C.S. Leucemia mielóide crônica: História natural e classificação. Rev. Bras. Hematol. Hemoter. 2008, 30, 3-7. [CrossRef]

8. Rowley, J.D. A story of swapped ends. Science 2013, 340, 1412-1413. [CrossRef]

9. Arber, D.A.; Orazi, A.; Hasserjian, R.; Thiele, J.; Borowitz, M.; Le Beau, M.; Bloomfield, C.; Cazzola, M.; Vardiman, J. The 2016 revision to the World Health Organization classification of myeloid neoplasms and acute leukemia. Blood 2016, 127, $2391-2405$. [CrossRef]

10. Barbui, T.; Thiele, J.; Gisslenger, H.; Kvasnicka, H.M.; Vannucchi, A.; Guglielmelli, P.; Orazi, A.; Tefferi, A. The 2016 WHO classification and diagnostic criteria for myeloproliferative neoplasms: Document summary and in-depth discussion. Blood Cancer J. 2018, 8, 15. [CrossRef]

11. Ortmann, C.A.; Kent, D.G.; Nangalia, J.; Silber, Y.; Wedge, D.C.; Grinfeld, J.; Baxter, E.J.; Massie, C.E.; Papaemmanuil, E.; Menon, S.; et al. Effect of mutation order on myeloproliferative neoplasms. N. Engl. J. Med. 2015, 372, 601-612. [CrossRef] [PubMed]

12. Campbell, P.J.; Green, A.R. The myeloproliferative disorders. N. Engl. J. Med. 2006, 57, 428-435. [CrossRef] [PubMed]

13. Grinfeld, J.; Nangalia, J.; Baxter, E.J.; Wedge, D.C.; Angelopoulos, N.; Cantrill, J.; Godfrey, A.L.; Papaemmanuil, E.; Gundem, G.; MacLean, C.; et al. Classification and Personalized Prognosis in Myeloproliferative Neoplasms. N. Engl. J. Med. 2018, 379, 1416-1430. [CrossRef] [PubMed]

14. Szuber, N.; Vallapureddy, R.; Penna, D.; Lasho, T.L.; Finke, C.; Hanson, C.A.; Ketterling, R.P.; Pardanni, A.; Gangat, N.; Tefferi, A. Myeloproliferative neoplasms in the young: Mayo Clinic experience with 361 patients age 40 years or younger. Am. J. Hematol. 2018, 93, 1474-1484. [CrossRef]

15. Harrison, C.N.; Koschmieder, S.; Foltz, L.; Guglielmelli, P.; Flindt, T.; Koehler, M.; Mathias, J.; Komatsu, N.; Boothroyd, R.N.; Spierer, A.; et al. The impact of myeloproliferative neoplasms (MPNs) on patient quality of life and productivity: Results from the international MPN Landmark survey. Ann. Hematol. 2017, 96, 1653-1665. [CrossRef]

16. Tefferi, A.; Pardanani, A. Myeloproliferative Neoplasms: A Contemporary Review. JAMA Oncol. 2015, 1, 97-105. [CrossRef]

17. Meyer, S.; Levine, R.S. Molecular Pathways: Molecular Basis for Sensitivity and Resistance to JAK Kinase Inhibitors. Clin. Cancer Res. 2014, 15, 2051-2059. [CrossRef]

18. Lundberg, P.; Karow, A.; Nienhold, R.; Looser, R.; Hao-Shen, H.; Nissen, I.; Girsberger, S.; Lehmann, T.; Passweg, J.; Stern, M.; et al. Clonal evolution and clinical correlates of somatic mutations in myeloproliferative neoplasms. Blood 2014, 123, 2220-2228. [CrossRef]

19. Papaemmanuil, E.; Gerstung, M.; Malcovati, L.; Tauro, S.; Gundem, G.; Van Loo, P.; Yoon, C.J.; Ellis, P.; Wedge, D.C.; Pellagatti, A.; et al. Clinical and biological implications of driver mutations in myelodysplastic syndromes. Blood 2013, 122, 3616-3627. [CrossRef]

20. Guglielmelli, P.; Lasho, T.L.; Rotunno, G.; Score, J.; Mannarelli, C.; Pancrazzi, A.; Biamonte, F.; Pardanani, A.; Zoi, K.; Reiter, A.; et al. The number of prognostically detrimental mutations and prognosis in primary myelofibrosis: An international study of 797 patients. Leukemia 2014, 28, 1804-1810. [CrossRef]

21. Kralovics, R.; Stockton, D.W.; Prchal, J.T. Clonal hematopoiesis in familial polycythemia vera suggests the involvement of multiple mutational events in the early pathogenesis of the disease. Blood 2003, 102, 3793-3796. [CrossRef] [PubMed]

22. Rumi, E.; Harutyunyan, A.S.; Pietra, D.; Milosevic, J.D.; Casetti, I.C.; Bellini, M.; Them, N.C.C.; Cavalloni, C.; Ferretti, V.V.; Milanesi, C.; et al. CALR exon 9 mutations are somatically acquired events in familial cases of essential thrombocythemia or primary myelofibrosis. Blood 2014, 123, 2416-2419. [CrossRef] [PubMed]

23. Landgren, O.; Goldin, L.R.; Kristinsson, S.Y.; Helgadottir, E.A.; Samuelsson, J.; Björkholm, M. Increased risks of polycythemia vera, essential thrombocythemia, and myelofibrosis among 24,577 first-degree relatives of 11,039 patients with myeloproliferative neoplasms in Sweden. Blood 2008, 112, 2199-2204. [CrossRef] [PubMed]

24. Langabeer, S.E.; Haslam, K.; Linders, J.; Percy, M.J.; Conneally, E.; Hayat, A.; Hennessy, B.; Leahy, M.; Murphy, K.; Murray, M.; et al. Molecular heterogeneity of familial myeloproliferative neoplasms revealed by analysis of the commonly acquired JAK2, CALR and MPL mutations. Fam. Cancer. 2014, 13, 659-663. [CrossRef] [PubMed]

25. Higgs, J.R.; Sadek, I.; Neumann, P.E.; Ing, V.W.; Renault, N.K.; Berman, J.N.; Greer, W.L. Familial essential thrombocythemia with spontaneous megakaryocyte colony formation and acquired JAK2 mutations. Leukemia 2008, 22, 1551-1556. [CrossRef]

26. Aljabry, M. Primary familial and congenital polycythemia; The forgotten entity. J. Appl. Hematol. 2018, 9, 39-43. [CrossRef]

27. Mounier, N. Malignant hematology. Oncologie 2008, 10, 512-514. [CrossRef]

28. Milosevic, J.D.; Nivarthi, H.; Gisslinger, H.; Leroy, E.; Rumi, E.; Chachoua, I.; Bagienski, K.; Kubesova, B.; Pietra, D.; Gisslinger, B.; et al. Whole-exome sequencing identifies novel MPL and JAK2 mutations in triple-negative myeloproliferative neoplasms. Blood 2016, 127, 325-332. [CrossRef]

29. De Freitas, R.M.; da Costa Maranduba, C.M. Myeloproliferative neoplasms and the JAK/STAT signaling pathway: An overview. Rev. Bras. Hematol. Hemot. 2015, 37, 348-353. [CrossRef]

30. Tefferi, A.; Barbui, T. Polycythemia vera and essential thrombocythemia: 2019 update on diagnosis, risk-stratification and management. Am. J. Hematol. 2019, 2, 133-143. [CrossRef]

31. Vainchenker, W.; Kralovics, R. Genetic basis and molecular pathophysiology of classical myeloproliferative neoplasms. Blood 2017, 129, 667-679. [CrossRef] [PubMed] 
32. Bousoik, E.; Aliabadi, H.M. Do We Know Jack2 about JAK? A Closer Look at JAK/STAT Signaling Pathway. Front. Oncol. 2018, 8, 287. [CrossRef] [PubMed]

33. Milosevic, J.D.; Schischlik, F.; Jäger, R.; Ivanov, D.; Eisenwort, G.; Keller, A.; Schuster, M.; Hadzijusufovic, E.; Krauth, M.; Spörk, R.; et al. Overexpression of PD-L1 Correlates with JAK2-V617F Mutational Burden and Is Associated with Chromosome 9p Uniparental Disomy in MPN. Blood 2020, 136, 24. [CrossRef]

34. Koschmieder, S.; Mughal, T.; Hasselbalch, H.C.; Barosi, G.; Valent, P.; Kiladjian, J.; Jeryczynski, G.; Gisslinger, H.; Jutzi, J.S.; Pahl, H.L.; et al. Myeloproliferative neoplasms and inflammation: Whether to target the malignant clone or the inflammatory process or both. Leukemia 2016, 30, 1018-1024. [CrossRef]

35. Gleitz, H.; Dugourd, A.J.F.; Leimkuhler, N.B.; Snoeren, I.A.M.; Fuchs, S.N.; Menzel, S.; Ziegler, S.; Kroger, N.; Triviai, I.; Busche, G.; et al. Increased CXCL4 expression in hematopoietic cells links inflammation and progression of bone marrow fibrosis in MPN. Blood 2020, 136, 2051-2064. [CrossRef]

36. Verstovsek, S.; Manshouri, T.; Pilling, D.; Bueso-Ramos, C.E.; Newberry, K.J.; Prijic, S.; Knez, L.; Bozinovic, K.; Harris, D.M.; Spaeth, E.L.; et al. Role of neoplastic monocyte-derived fibrocytes in primary myelofibrosis. J. Exp. Med. 2016, 213, 1723-1740. [CrossRef]

37. Baxter, E.J.; Scott, L.M.; Campbell, P.J.; East, C.; Fourouclas, N.; Swanton, S.; Vassiliou, G.S.; Bench, A.J.; Boyd, E.M.; Curtin, N.; et al. Acquired mutation of the tyrosine kinase JAK2 in human myeloproliferative disorders. Lancet 2005, 365, $1054-1061$. [CrossRef]

38. Levine, R.L.; Wadleigh, M.; Cools, J.; Ebert, B.L.; Wernig, G.; Huntly, B.J.P.; Boggon, T.J.; Wlodarska, I.; Clark, J.J.; Moore, S.; et al. Activating mutation in the tyrosine kinase JAK2 in polycythemia vera, essential thrombocythemia, and myeloid metaplasia with myelofibrosis. Cancer Cell. 2005, 7, 387-397. [CrossRef]

39. Kralovics, R.; Passamonti, F.; Buser, A.S.; Teo, S.-S.; Tiedt, R.; Passweg, J.R.; Tichelli, A.; Cazzola, M.; Skoda, R.C. A Gain-ofFunction Mutation of JAK2 in Myeloproliferative Disorders. N. Engl. J. Med. 2005, 352, 1779-1790. [CrossRef]

40. James, C.; Ugo, V.; Le Couédic, J.P.; Staerk, J.; Delhommeau, F.; Lacout, C.; Garçon, L.; Raslova, H.; Berger, R.; Bennaceur-Griscelli, A.; et al. A unique clonal JAK2 mutation leading to constitutive signalling causes polycythaemia vera. Nature 2005, 434, 1144-1148. [CrossRef]

41. Abdulqader, A.; Saeed, B.; Getta, H.A.; Khoshnaw, N.; Abdulqader, G.; Mohammed, A. Prevalence of JAK2 V617F, CALR, and MPL W515L Gene Mutations in Patients with Essential Thrombocythemia in Kurdistan Region of Iraq. Korean J. Clin. Lab. Sci. 2021, 53, 41-48. [CrossRef]

42. Staerk, J.; Constantinescu, S.N. The JAK-STAT pathway and hematopoietic stem cells from the JAK2 V617F perspective. JAK-STAT. 2012, 1, 184-190. [CrossRef] [PubMed]

43. Hermouet, S.; Vilaine, M. The JAK2 46/1 haplotype: A marker of inappropriate myelomonocytic response to cytokine stimulation, leading to increased risk of inflammation, myeloid neoplasm, and impaired defense against infection? Haematologica 2011, 96, 1575-1579. [CrossRef] [PubMed]

44. Olcaydu, D.; Rumi, E.; Harutyunyan, A.; Passamonti, F.; Pietra, D.; Pascutto, C.; Berg, T.; Jäger, R.; Hammond, E.; Cazzola, M.; et al. The role of the JAK2 GGCC haplotype and the TET2 gene in familial myeloproliferative neoplasms. Haematologica 2011, 96, 367-374. [CrossRef]

45. Jones, A.V.; Cross, N.C.P. Inherited predisposition to myeloproliferative neoplasms. Ther. Adv. Hematol. 2013, 4, 237-253. [CrossRef]

46. Tashi, T.; Swierczek, S.; Prchal, J.T. Familial MPN Predisposition. Curr. Hematol. Malig. Rep. 2017, 12, 442-447. [CrossRef]

47. Koh, S.P.; Yip, S.P.; Lee, K.K.; Chan, C.C.; Lau, S.M.; Kho, C.S.; Lau, C.K.; Lin, S.Y.; Lau, Y.M.; Wong, L.G.; et al. Genetic association between germline JAK2polymorphisms and myeloproliferative neoplasms in Hong Kong Chinese population: A case-control study. BMC Genet. 2014, 15, 147. [CrossRef]

48. Hinds, D.A.; Barnholt, K.E.; Mesa, R.A.; Kiefer, A.K.; Do, C.B.; Eriksson, N.; Mountain, J.L.; Francke, U.; Tung, J.Y.; Nguyen, H.; et al. Germ line variants predispose to both JAK2 V617F clonal hematopoiesis and myeloproliferative neoplasms. Blood 2016, 128, 1121-1128. [CrossRef]

49. Owen, K.L.; Brockwell, N.K.; ParkerImmune, B.S. JAK-STAT Signaling: A Double-Edged Sword of Immune Regulation and Cancer Progression. Cancers 2019, 11, 2002. [CrossRef]

50. Ferrer-Marín, F.; Cuenca-Zamora, E.J.; Guijarro-Carrillo, P.J.; Teruel-Montoya, R. Emerging role of neutrophils in the thrombosis of chronic myeloproliferative neoplasms. Int. J. Mol. Sci. 2021, 22, 1143. [CrossRef]

51. Landolfi, R.; Di Gennaro, L. Pathophysiology of thrombosis in myeloproliferative neoplasms. Haematologica 2011, 96, 183-186. [CrossRef] [PubMed]

52. Wang, W.; Liu, W.; Fidler, T.; Wang, Y.; Tang, Y.; Woods, B.; Welch, C.; Cai, B.; Silvestre-Roig, C.; Ai, D.; et al. Macrophage inflammation, erythrophagocytosis, and accelerated atherosclerosis in JAK2V617F mice. Circ. Res. 2018, 123, 35-47. [CrossRef] [PubMed]

53. Marin Oyarzún, C.P.; Heller, P.G. Platelets as mediators of thromboinflammation in chronic myeloproliferative neoplasms. Front. Immunol. 2019, 10, 1373. [CrossRef] [PubMed]

54. Vannucchi, A.M.; Guglielmelli, P. What are the current treatment approaches for patients with polycythemia vera and essential thrombocythemia? Hematology 2017, 1, 480-488. [CrossRef] 
55. Wolach, O.; Abulafia, A.S. Can Novel Insights into the Pathogenesis of Myeloproliferative Neoplasm-Related Thrombosis Inform Novel Treatment Approaches? Hemato 2021, 2, 305-328. [CrossRef]

56. Marín, C.P.; Glembotsky, A.C.; Goette, N.P.; Lev, P.R.; de Luca, G.; Baroni, M.C.; Moiraghi, B.; Castro, M.A.; Vicente, A.; Marta, R.F.; et al. Platelet Toll-Like Receptors Mediate Thromboinflammatory Responses in Patients With Essential Thrombocythemia. Front. Immunol. 2020, 11, 705. [CrossRef]

57. Di Rosa, M.; Giallongo, C.; Romano, A.; Li Volti, G.; Musumeci, G.; Barbagallo, I.; Castrogiovanni, P.; Palumbo, G.A. Immunoproteasome genes are modulated in CD34+ JAK2V617F mutated cells from primary myelofibrosis patients. Int. J. Mol. Sci. 2020, 21, 2926. [CrossRef]

58. Davis, Z.; Felices, M.; Lenvik, T.; Badal, S.; Walker, J.T.; Hinderlie, P.; Riley, J.L.; Vallera, D.A.; Blazar, B.R.; Miller, J.S. Low-density PD-1 expression on resting human natural killer cells is functional and upregulated after transplantation. Blood Adv. 2021, 5, 1069-1080. [CrossRef]

59. Perner, F.; Perner, C.; Ernst, T.; Heidel, F.H. Roles of JAK2 in Aging, Inflammation, Hematopoiesis and Malignant Transformation Cells 2019, 8, 854. [CrossRef]

60. Prestipino, A.; Emhardt, A.J.; Aumann, K.; O’Sullivan, D.; Gorantla, S.P.; Duquesne, S.; Melchinger, W.; Braun, L.; Vuckovic, S.; Boerries, M.; et al. Oncogenic JAK2V617F causes PD-L1 expression, mediating immune escape in myeloproliferative neoplasms. Sci. Transl. Med. 2019, 10, eaam7729. [CrossRef]

61. Ginzburg, Y.Z.; Feola, M.; Zimran, E.; Varkonyi, J.; Ganz, T.; Hoffman, R. Dysregulated iron metabolism in polycythemia vera: Etiology and consequences. Leukemia 2018, 32, 2105-2116. [CrossRef] [PubMed]

62. Allain-Maillet, S.; Bosseboeuf, A.; Mennesson, N.; Bostoën, M.; Dufeu, L.; Choi, E.H.; Cleyrat, C.; Mansier, O.; Lippert, E.; Le Bris, J.; et al. Anti-Glucosylsphingosine Autoimmunity, JAK2V617F-Dependent Interleukin-1 $\beta$ and JAK2V617FIndependent Cytokines in Myeloproliferative Neoplasms. Cancers 2020, 12, 2446. [CrossRef] [PubMed]

63. Hermouet, S.; Bigot-Corbel, E.; Gardie, B. Pathogenesis of Myeloproliferative Neoplasms: Role and Mechanisms of Chronic Inflammation. Mediat. Inflamm. 2015, 2015, 145293. [CrossRef] [PubMed]

64. Oyarzún, C.; Carestia, A.; Lev, P.R.; Glembotsky, A.C.; Castro, M.A.; Moiraghi, B.; Molinas, F.C.; Marta, R.F.; Schattner, M.; Heller, P.G. Neutrophil extracellular trap formation and circulating nucleosomes in patients with chronic myeloproliferative neoplasms. Sci. Rep. 2016, 6, 38738. [CrossRef]

65. Wolach, O.; Sellar, R.S.; Martinod, K.; Cherpokova, D.; McConkey, M.; Chappell, R.J.; Silver, A.J.; Adams, D.; Castellano, C.A.; Schneider, R.K.; et al. Increased neutrophil extracellular trap formation promotes thrombosis in myeloproliferative neoplasms. Sci. Transl. Med. 2018, 10, eaan8292. [CrossRef]

66. Oh, S.T. Neutralize the neutrophils! Neutrophil $\beta 1 / \beta 2$ integrin activation contributes to JAK2-V617F-driven thrombosis. J. Clin. Investig. 2018, 128, 4248-4250. [CrossRef]

67. Gupta, N.; Edelmann, B.; Schnoeder, T.M.; Saalfeld, F.C.; Wolleschak, D.; Kliche, S.; Schraven, B.; Heidel, F.H.; Fischer, T. JAK2V617F activates $\beta 1$-integrin-mediated adhesion of granulocytes to vascular cell adhesion molecule. Leukemia 2017, 31, 1223-1226. [CrossRef]

68. Edelmann, B.; Gupta, N.; Schnoeder, T.M.; Oelschlegel, A.M.; Shahzad, K.; Goldschmidt, J.; Philipsen, L.; Weinert, S.; Ghosh, A.; Saalfeld, F.C.; et al. JAK2-V617F promotes venous thrombosis through $\beta 1 / \beta 2$ integrin activation. J. Clin. Investig. 2018, 128, 4359-4371. [CrossRef]

69. Haage, T.R.; Müller, A.J.; Arunachalam, P.; Fischer, T. Reveal the Neutrophil: Elucidating the Role of a Neutrophil-Specific JAK2-V617F Mutation. Blood 2019, 134, 2965. [CrossRef]

70. Gaertner, F.; Massberg, S. Blood coagulation in immunothrombosis-At the frontline of intravascular immunity. Semin. Immunol. 2016, 28, 561-569. [CrossRef]

71. Shi, C.; Yang, L.; Braun, A.; Anders, H.J. Extracellular DNA—A Danger Signal Triggering Immunothrombosis. Front. Immunol. 2020, 11, 2518. [CrossRef] [PubMed]

72. Yang, J.; Wu, Z.; Long, Q.; Huang, J.; Hong, T.; Liu, W.; Lin, J. Insights into Immunothrombosis: The Interplay Among Neutrophil Extracellular Trap, von Willebrand Factor, and ADAMTS13. Front. Immunol. 2020, 11, 3116. [CrossRef] [PubMed]

73. McKenna, E.; Mhaonaigh, A.U.; Wubben, R.; Dwivedi, A.; Hurley, T.; Kelly, L.A.; Stevenson, N.J.; Little, M.A.; Molloy, E.J Neutrophils: Need for Standardized Nomenclature. Front. Immunol. 2021, 12, 1081. [CrossRef] [PubMed]

74. Shaul, M.E.; Fridlender, Z.G. Cancer-related circulating and tumor-associated neutrophils-Subtypes, sources and function. FEBS J. 2018, 285, 4316-4342. [CrossRef] [PubMed]

75. Giese, M.A.; Hind, L.E.; Huttenlocher, A. Neutrophil plasticity in the tumor microenvironment. Blood 2019, $133,2159-2167$. [CrossRef]

76. Masucci, M.T.; Minopoli, M.; Carriero, M.V. Tumor Associated Neutrophils. Their Role in Tumorigenesis, Metastasis, Prognosis and Therapy. Front. Oncol. 2019, 9, 1146. [CrossRef]

77. Piccard, H.; Muschel, R.J.; Opdenakker, G. On the dual roles and polarized phenotypes of neutrophils in tumor development and progression. Crit. Rev. Oncol. Hematol. 2012, 82, 296-309. [CrossRef]

78. Podaza, E.; Risnik, D. Neglected players: Tumor associated neutrophils involvement in chronic lymphocytic leukemia progression. Oncotarget 2019, 10, 1862-1863. [CrossRef] 
79. Castiglione, M.; Jiang, Y.P.; Mazzeo, C.; Lee, S.; Chen, J.S.; Kaushansky, K.; Yin, W.; Lin, R.Z.; Zheng, H.; Zhan, H. Endothelial JAK2V617F mutation leads to thrombosis, vasculopathy, and cardiomyopathy in a murine model of myeloproliferative neoplasm". J. Thromb. Haemost. 2020, 18, 3359-3370. [CrossRef]

80. Conran, N.; de Paula, E.V. Thromboinflammatory mechanisms in sickle cell disease-Challenging the hemostatic balance. Haematologica 2020, 105, 2380-2390. [CrossRef]

81. Poisson, J.; Tanguy, M.; Davy, H.; Camara, F.; El Mdawar, M.B.; Kheloufi, M.; Dagher, T.; Devue, C.; Plessier, J.A.; Merchant, S.; et al. Erythrocyte-derived microvesicles induce arterial spasms in JAK2V617F myeloproliferative neoplasm. J. Clin. Investig. 2020, 130, 2630-2643. [CrossRef] [PubMed]

82. Murata, M. Inflammation and cancer. Environ. Health Prev. Med. 2018, 23, 1-8. [CrossRef] [PubMed]

83. Lussana, F.; Rambaldi, A. Inflammation and myeloproliferative neoplasms. J. Autoimmun. 2017, 85, 58-63. [CrossRef] [PubMed]

84. Arellano-Rodrigo, E.; Alvarez-Larra, A.; Reverter, J.C.; Colomer, D.; Villamor, N.; Bellosillo, B.; Cervantes, F. Platelet turnover, coagulation factors, and soluble markers of platelet and endothelial activation in essential thrombocythemia: Relationship with thrombosis occurrence and JAK 2 V617F allele burden. Am. J. Hematol. 2008, 84, 102-108. [CrossRef]

85. Kaifie, A.; Kirschner, M.; Wolf, D.; Maintz, C.; Hänel, M.; Gattermann, N.; Gökkurt, E.; Platzbecker, U.; Hollburg, W.; Göthert, J.R.; et al. Bleeding, thrombosis, and anticoagulation in myeloproliferative neoplasms (MPN): Analysis from the German SAL-MPN-registry. J. Hematol. Oncol. 2016, 9, 18. [CrossRef]

86. Yonal-Hindilerden, I.; Daglar-Aday, A.; Akadam-Teker, B.; Yilmaz, C.; Nalcaci, M.; Yavuz, A.S.; Dargin, D. Mutations and JAK2V617F allele burden in Philadelphia-negative myeloproliferative neoplasms. J. Blood Med. 2015, 6, 157-176. [CrossRef]

87. Matsuura, S.; Thompson, C.R.; Belghasem, M.E.; Bekendam, R.H.; Piasecki, A.; Leiva, O.; Ray, A.; Italiano, J.; Yang, M.; MerillSkoloff, G.; et al. Platelet dysfunction and thrombosis in JAK2V617F-mutated primary myelofibrotic mice. Arterioscler. Thromb. Vasc. Biol. 2020, 40, 262-272. [CrossRef]

88. Greenfield, G.; McMullin, M.F.; Mills, K. Molecular pathogenesis of the myeloproliferative neoplasms. J. Hematol. Oncol. 2021, 14, 103. [CrossRef]

89. Leimk€uhler, N.B.; Gleitz, H.F.E.; Ronghui, L.; Snoeren, I.A.M.; Fuchs, S.N.R.; Nagai, J.S.; Banjanin, B.; Lam, K.H.; Vogl, T.; Kuppe, C.; et al. Heterogeneous bone-marrow stromal progenitors drive myelofibrosis via a druggable alarmin axis. Cell Stem Cell. 2021, 28, 637-652. [CrossRef]

90. Goette, N.P.; Lev, P.R.; Heller, P.G.; Kornblihtt, L.I.; Korin, L.; Molinas, F.C.; Marta, R.F. Monocyte IL-2R $\alpha$ expression is associated with thrombosis and the JAK2V617F mutation in myeloproliferative neoplasms. Cytokine 2010, 51, 67-72. [CrossRef]

91. Margraf, A.; Zarbock, A. Platelets in Inflammation and Resolution. J. Immunol. 2019, 203, 2357-2367. [CrossRef] [PubMed]

92. Brostjan, C.; Oehler, R. The role of neutrophil death in chronic inflammation and cancer. Cell Death Discov. 2020, 6, 26. [CrossRef] [PubMed]

93. Wang, L.; Zhang, S.; Wu, H.J.; Rong, X.; Guo, J. M2b macrophage polarization and its roles in diseases. J. Leukoc. Biol. 2019, 106, 345-358. [CrossRef] [PubMed]

94. Molitor, D.C.; Boor, P.; Buness, A.; Schneider, R.K.; Teichmann, L.L.; Körber, R.M.; Horvath, G.L.; Koschmieder, S.; Gütgemann, I. Macrophage frequency in the bone marrow correlates with morphologic subtype of myeloproliferative neoplasm. Ann. Hematol. 2021, 100, 97-104. [CrossRef] [PubMed]

95. Larsen, T.S.; Christensen, J.H.; Hasselbalch, H.C.; Pallisgaard, N. The JAK2 V617F mutation involves B- and T-lymphocyte lineages in a subgroup of patients with Philadelphia-chromosome negative chronic myeloproliferative disorders. Br. J. Haematol. 2007, 36, 745-751. [CrossRef] [PubMed]

96. Nicolosi, M.; Mudireddy, M.; Gangat, N.; Pardanani, A.; Hanson, C.A.; Ketterling, R.P.; Tefferi, A. Normal karyotype in myelofibrosis: Is prognostic integrity affected by the number of metaphases analyzed? Blood Cancer J. 2018, 8, 8. [CrossRef]

97. Tefferi, A.; Nicolosi, M.; Mudireddy, M.; Lasho, T.L.; Gangat, N.; Begna, K.H.; Hanson, C.A.; Ketterling, R.P.; Pardanani, A. Revised cytogenetic risk stratification in primary myelofibrosis: Analysis based on 1002 informative patients. Leukemia 2018, 32, 1189-1199. [CrossRef]

98. Gonzalez-Rodriguez, A.P.; Villa-Álvarez, M.; Sordo-Bahamonde, C.; Lorenzo-Herrero, S.; Gonzalez, S. NK Cells in the Treatment of Hematological Malignancies. J. Clin. Med. 2019, 8, 1557. [CrossRef]

99. Arantes, A.; Leal, C.; Araújo, C.; Santos, P.; Bergamo, A.; Welner, R.S.; Tenen, D.G.; Mullally, A.; Kobayashi, S.; Magalhaes, E.; et al. Decreased Activity of NK Cells in Myeloproliferative Neoplasms. Blood 2015, 126, 1637. [CrossRef]

100. Palumbo, G.A.; Stella, S.; Pennisi, M.S.; Pirosa, C.; Fermo, E.; Fabris, S.; Cattaneo, D.; Iurlo, A. The Role of New Technologies in Myeloproliferative Neoplasms. Front. Oncol. 2019, 9, 321. [CrossRef]

101. Helbig, G. Classical Philadelphia-negative myeloproliferative neoplasms: Focus on mutations and JAK2 inhibitors. Med. Oncol. 2018, 35, 119. [CrossRef] [PubMed]

102. Skov, V. Next Generation Sequencing in MPNs. Lessons from the Past and Prospects for Use as Predictors of Prognosis and Treatment Responses. Cancers 2021, 12, 2194. [CrossRef] [PubMed]

103. Patnaik, M.M.; Lasho, T.L. Genomics of myelodysplastic syndrome/myeloproliferative neoplasm overlap syndromes. Hematology 2020, 20, 450-459. [CrossRef] [PubMed]

104. Luque Paz, D.; Jouanneau-Courville, R.; Riou, J.; Ianotto, J.C.; Boyer, F.; Chauveau, A.; Renard, M.; Chomel, J.C.; Cayssials, E.; Gallego-Hernanz, M.P.; et al. Leukemic evolution ofpolycythemia vera and essential thrombocythemia: Genomic profiles predict time to transformation. Blood Adv. 2020, 4, 4887-4897. [CrossRef] [PubMed] 
105. Vannucchi, A.M. From leeches to personalized medicine: Evolving concepts in the management of polycythemia vera. Haematologica 2017, 102, 18-29. [CrossRef] [PubMed]

106. Moliterno, A.; Kaizer, H. Applied genomics in MPN presentation. Hematology 2020, 2020, 434-439. [CrossRef]

107. Downes, C.E.J.; McClure, B.J.; Rehn, J.; Breen, J.; Bruning, J.B.; Yeung, D.T.; White, D.L. Acquired Mutations within the JAK2 Kinase Domain Confer Resistance to JAK Inhibitors in an in Vitro model of a High-Risk Acute Lymphoblastic Leukemia. Blood 2020, 136, 5-6. [CrossRef]

108. Helbig, G.; Wichary, R.; Torba, K.; Kyrcz-Krzemien, S. Resolution of thrombocytopenia, but not polycythemia after ruxolitinib for polycythemia vera with detectable mutation in the exon 12 of the JAK2 gene. Med. Oncol. 2017, 34, 31. [CrossRef]

109. Habbel, J.; Arnold, L.; Chen, Y.; Möllmann, M.; Bruderek, K.; Brandau, S.; Dührsen, U.; Hanoun, M. Inflammation-driven activation of JAK/STAT signaling reversibly accelerates acute myeloid leukemia in vitro. Blood Adv. 2020, 4, 3000-3010. [CrossRef]

110. Forte, D.; Barone, M.; Palandri, F.; Catani, L. The "Vesicular Intelligence" Strategy of Blood Cancers. Genes 2021, 12, 416. [CrossRef]

111. Garcia-Gisbert, N.; Fernandez-Ibarrondo, L.; Fernandez-Rodrıguez, C.; Gibert, J.; Andrade-Campos, M.; Arenillas, L.; Camacho, L.; Angona, A.; Longaron, R.; Salar, A.; et al. Circulating cell-free DNA improves the molecular characterisa- tion of Ph-negative myeloproliferative neoplasms. Br. J. Haematol. 2021, 192, 300-309. [CrossRef] [PubMed]

112. Găman, M.A.; Cozma, M.A.; Dobrică, E.C.; Cretoiu, S.M.; Găman, A.M.; Diaconu, C.C. Liquid Biopsy and Potential Liquid Biopsy-Based Biomarkers in Philadelphia-Negative Classical Myeloproliferative Neoplasms: A Systematic Review. Life 2021, 11, 677. [CrossRef] [PubMed] 